\title{
Differential expression of cyclin D1, Ki-67, pRb, and p53 in psoriatic skin lesions and normal skin
}

\author{
SUNG AE KIM ${ }^{1}$, YOUNG WOOK RYU ${ }^{1}$, JUN IL KWON ${ }^{1}$, MI SUN CHOE ${ }^{2}$, \\ JIN WOONG JUNG ${ }^{1}$ and JAE WE CHO ${ }^{1}$ \\ Departments of ${ }^{1}$ Dermatology and ${ }^{2}$ Pathology, Keimyung University School \\ of Medicine, Jung-Gu, Daegu 41931, Republic of Korea
}

Received October 5, 2016; Accepted March 31, 2017

DOI: $10.3892 / \mathrm{mmr} .2017 .8015$

\begin{abstract}
Psoriasis is a hyperproliferative inflammatory skin disease; therefore, it is highly likely that psoriatic skin lesions may transform into malignancies. However, malignant transformation is not common. We performed immunohistochemical studies using anti-cyclin D1, anti-cyclin E, anti-pRb, anti-p53, anti-p16INK4a, and anti-Ki-67 antibodies in normal skin, psoriatic epidermal tissue, and squamous cell carcinoma (SCC) tissue. Furthermore, western blot analysis and immunohistochemical staining were performed to ascertain differences in cyclin D1, cyclin E, pRb, and Ki-67 expression before and after treatment for psoriasis. Cyclin D1 expression was higher in chronic psoriatic lesions than that in normal epidermis. Psoriasis lesions showed a strong intensity of positive nuclear staining for cyclin D1 among several normally stained nuclei in the basal layer. Cyclin E expression in psoriasis was stronger in the granular and spinous layer than in the normal epidermis. Expression levels of $\mathrm{pRb}$ and p53 were found to be higher in the psoriasis group compared with the normal epidermis. Total basal layer cell counts for $\mathrm{p} 53^{\mathrm{WT}}$ expression were found to be significantly higher in the psoriasis group compared with the normal group. However, p16 expression was very weak in the normal and psoriasis groups compared with that in the SCC group. Ki-67 immunoreactivity was significantly higher in psoriasis compared with normal epidermis and was similar with that in the SCC group. According to immunohistochemistry and immunoblot analysis, the expression levels of cyclin D1, cyclin E, pRb, and $\mathrm{Ki}-67$ in psoriasis lesions decreased after treatment and were similar with those in the normal group. Thus, increased expression of cyclin D1 and cyclin E may be involved in cell cycle progression in psoriatic epidermis, and pRb and p53 may play important roles in the
\end{abstract}

Correspondence to: Dr Jae We Cho, Department of Dermatology, Keimyung University School of Medicine, 56 Dalseong-Ro, Jung-Gu, Daegu 41931, Republic of Korea

E-mail: janylove99@hanmail.net

Key words: psoriasis, cyclin D1, Ki-67, p53,pRb prevention of malignant transformation under the hyperproliferative state in psoriasis.

\section{Introduction}

Psoriasis vulgaris is one of the most proliferative inflammatory skin diseases in humans. Histologically, psoriasis is characterized by epidermal thickening as a result of abnormal proliferation, impaired maturation of keratinocytes, leucocyte infiltration, and new blood vessel formation (angiogenesis) $(1,2)$. Keratinocytes of psoriatic skin can reach the surface of the skin from the basal layer in just 6-8 days, compared to 30 days in normal skin (3). Studies have found the growth and proliferation of psoriatic keratinocytes to be intrinsically dysregulated by several mechanisms. First, phosphatase and tensin homolog (PTEN) expression is downregulated in psoriatic lesions by overactivation of the phosphoinositide-3 kinase/protein kinase-B (PI3K/Akt) pathway. It is also correlated with the hyperproliferation of psoriatic keratinocytes (4). Interestingly, the PI3K/Akt pathway is tightly linked with the extracellular signaling-regulated kinase (ERK)/mitogen-activated protein kinase (MAPK) pathway (5). Second, the final downstream target of the ERK/MAPK pathway is a positive cell cycle regulator, cyclin D1, which is overexpressed in psoriatic skin lesions (6-8). Third, FOS-like antigen 1 (Fra-1; a proto-oncogene) is highly expressed in tissues affected by psoriasis (9). Fra-1 also promotes the growth of HaCaT keratinocyte cell lines and inhibits the apoptosis of cells in vitro (9). Although it seems highly probable that psoriatic skin lesions can transform into malignancies by the accumulation of specific molecular events, skin cancer does not usually occur in psoriatic tissues.

Psoriatic skin is usually abnormally thickened compared to normal skin due to hyperproliferation of the epidermis. In fact, cell proliferation is accurately regulated by cell cycle regulatory proteins. Cyclin D1 and cyclin E are the key positive regulatory proteins involved in the progression of the G1/S transition phases (10-12). Therefore, the upregulation of cyclin D1 and cyclin E makes cells rapidly transition into G1/S phases, resulting in overall cell proliferation. Thus, the hyperproliferation of the epidermis is correlated with the upregulation of cyclin D1 or cyclin E in the epidermis. Under 
Table I. Expressions differences of cyclin D1, pRb, p53 and p16 between groups by Kruskal-Wallis test and post hoc test (Mann-Whitney U test).

\begin{tabular}{lccccccc}
\hline & \multicolumn{9}{c}{ Mean rank } & & & \\
\cline { 2 - 6 } Immunostaining & Control & $\begin{array}{c}\text { Acute } \\
\text { psoriasis }\end{array}$ & $\begin{array}{c}\text { Chronic } \\
\text { psoriasis }\end{array}$ & $\begin{array}{c}\text { Squamous } \\
\text { cell carcinoma }\end{array}$ & $\chi^{2}$ & P-value & $\begin{array}{c}\text { Post hoc } \\
\text { test }\end{array}$ \\
\hline Cyclin D1 & 4.5 & 3.0 & 9.0 & 12.5 & 10.352 & 0.016 & $3>2$ \\
pRb & 1.5 & 7.0 & 12.17 & 4.5 & 10.098 & 0.012 & $3>2$ \\
p53 & 1.5 & 5.2 & 9.8 & 13.5 & 11.301 & 0.010 & $3>2$ \\
Ki-67 & 1.5 & 5.6 & 11.50 & 10.00 & 9.740 & 0.021 & $3>2$ \\
\hline
\end{tabular}

the hyperproliferative state, $\mathrm{p} 53$ and pRb play important roles in preventing cancer formation by inducing apoptosis or by the senescence of hyperproliferated cells $(13,14)$. The expression of cell cycle regulatory proteins such as cyclin $\mathrm{D}$ and cyclin $\mathrm{E}$ and tumor suppressor proteins such as $\mathrm{p} 53$ and pRb have not been well investigated in psoriasis.

In this study, to elucidate why psoriasis does not transform into malignancy under keratinocyte hyperproliferation, we compared the expression levels of p53, pRb, and cell cycle regulatory proteins in psoriatic skin lesions with those in squamous cell carcinoma (SCC) tissues.s

\section{Materials and methods}

Materials. Antibodies against cell cycle regulatory proteins [cyclin D1 (no. sc-717), cyclin E (no. sc-481), p16 (no. sc-468), $\beta$-actin (no. sc-1616), and, Ki-67 (sc-7846)] were obtained from Santa Cruz Biotechnology (Santa Cruz, CA, USA). Anti-p53 (no. 48818) and anti-pRb (no. 554136) antibodies were purchased from Cell Signaling (Beverly, MA, USA) and PharMingen (BD Biosciences, CA, USA), respectively.

Patients. Twenty patients with psoriasis were enrolled for the study. The criteria for entry in the study were the manifestation of well-demarcated, erythematous, scaly psoriatic plaques on the trunk and extremities. Study subjects did not use any systemic anti-psoriatic treatments for 2 weeks before skin biopsy. Informed consent was obtained from all subjects under protocols approved by the Investigational Review Board of Dongsan Hospital of Keimyung University (IRB-09-28).

Immunoblot analysis. Tissues were prepared in lysis buffer [10 mM Tris (pH 7.4), $5 \mathrm{mM}$ EDTA, $130 \mathrm{mM} \mathrm{NaCl}$, $1 \%$ Triton $\mathrm{X}-100,50 \mathrm{mM}$ phenylmethylsulfonyl fluoride (PMSF), $10 \mathrm{mM}$ pepstatin A, $20 \mathrm{mM}$ leupeptin, $50 \mathrm{mM}$ bestatin, $100 \mathrm{mM}$ benzamidine, $10 \mathrm{mM}$ sodium fluoride, and $1 \mathrm{mM}$ sodium orthovanadate]. The protein concentrations of extracts were estimated with the Bradford reagent (Bio-Rad, Hercules, CA, USA) using bovine serum albumin as the standard. Equal amounts of protein ( $40 \mu \mathrm{g} /$ lane) were resolved by $6.5-12 \%$ sodium dodecyl sulfate-polyacrylamide gel electrophoresis and transferred onto a nitrocellulose membrane. The membrane was incubated with the respective specific antibodies (anti-pRb, anti-cyclin D1, anti-cyclin
E, and anti-p16). The membrane was continuously incubated with appropriate secondary antibodies coupled to horseradish peroxidase and developed in ECL western blotting detection reagents (Amersham Pharmacia Biotech, Piscataway, NJ, USA).

Immunohistochemistry. Formalin-fixed and paraffinembedded tissue specimens were cut on a microtome into $5-\mu \mathrm{m}$ thick sections. The sections were deparaffinized in xylenes and hydrated in alcohols of decreasing concentration. To visualize the antigen, the sections were heated in citrate buffer ( $\mathrm{pH}$ 6.0). After cooling to room temperature, 5-min incubation was performed with $\mathrm{H}_{2} \mathrm{O}_{2}$ to block endogenous peroxidase activity. After sections were rinsed in PBS (pH 7.4) for $15 \mathrm{~min}$ and blocked with the antibody diluent (Golden Bridge International, Mukilteo, WA, USA) for $5 \mathrm{~min}$, they were incubated with specific primary antibodies. Next, the anti-biotinyl antibody was used in the reaction, and the streptavidin-peroxidase complex $\left(\mathrm{LASB}^{\circledR}+\right.$ System-HRP; Dako, Carpintera, CA, USA) was applied. The antigen-antibody complex was visualized by DAB chromogen.

Immunohistochemical scoring and statistical analysis. The positively stained cells were counted (per $\mathrm{mm}^{2}$ ) for total epidermal immunostaining in the same x100 magnification field area. Data from the microscopic analysis were expressed as the mean \pm standard error. The Kruskal-Wallis one-way analysis of variance (ANOVA) and Mann-Whitney U test were used to compare the cell count $/ \mathrm{mm}^{2}$ as determined by immunostaining in the epidermal layers of the psoriasis group and the normal epidermis group. P-values of less than 0.05 were considered statistically significant. The statistical analysis was performed by using SPSS statistical software version 21.0 (SPSS, Chicago, IL, USA).

\section{Results}

Expression of cyclin D1, cyclin $E, p R b, p 53$, and $p 16$ in psoriasis. Cyclin D1 expression was clearly observed in the basal and suprabasal layers of the normal epidermis, showing positively stained nuclei. Cyclin D1 immunoreactivity in the normal epidermis was observed at regular intervals in the basal layer. Interestingly, psoriasis lesions showed a strong intensity of positive nuclear staining for cyclin D1 among several normally stained nuclei in the basal 

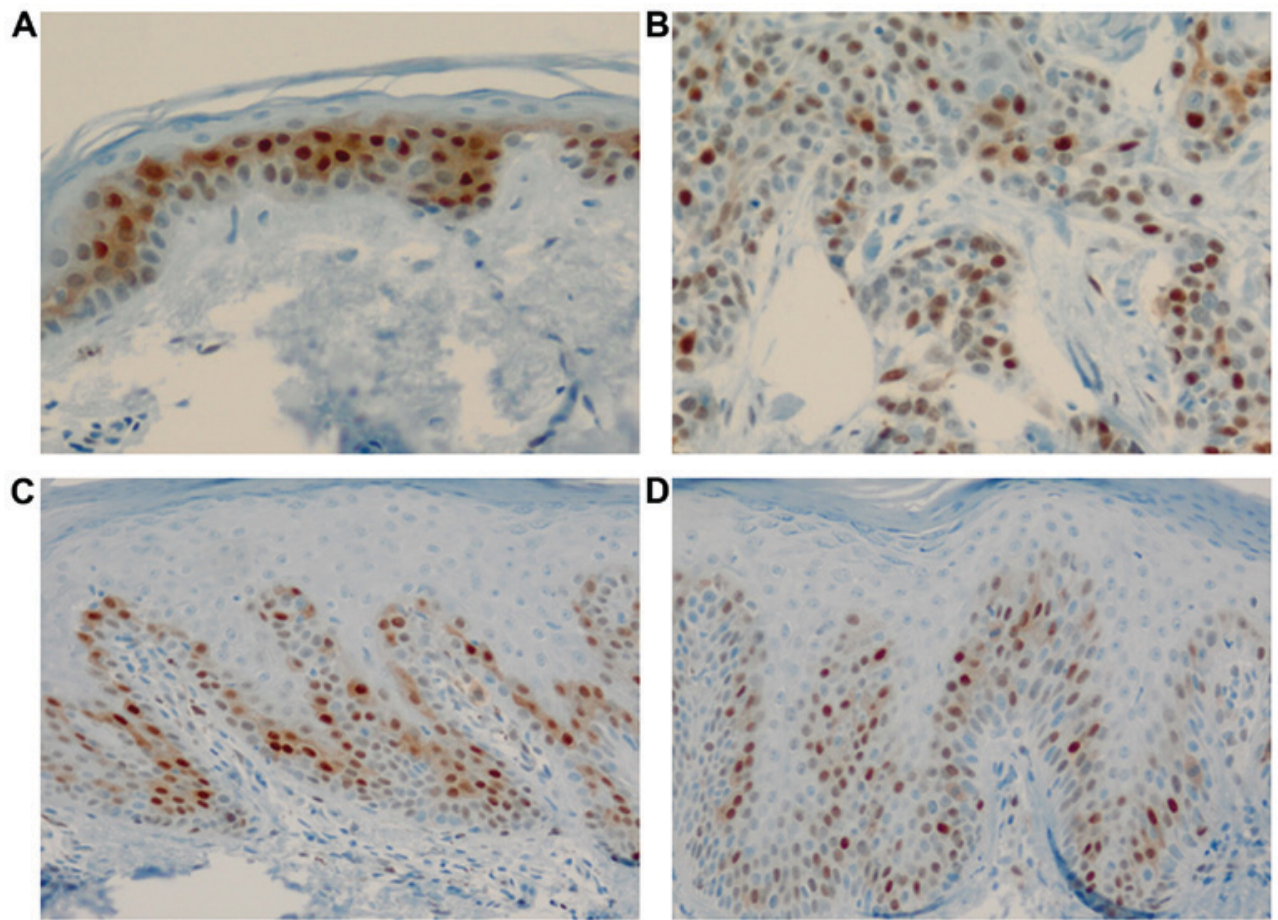

Figure 1. Cyclin D1 expression. Cyclin D1 expression in (A) control, (B) squamous cell carcinoma (SCC), (C) acute psoriasis, and (D) chronic psoriasis. Original magnification, x200.
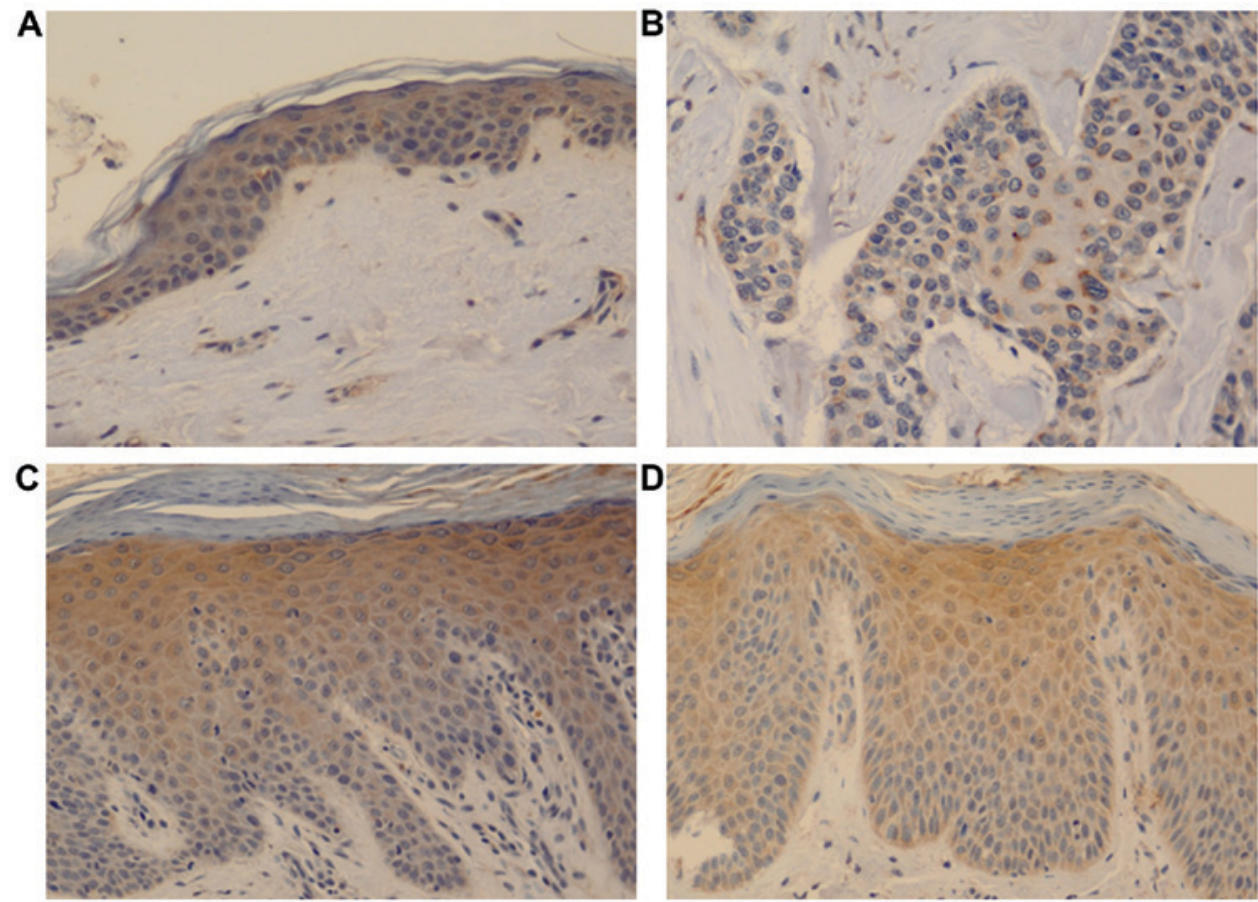

Figure 2. Cyclin E expression. Cyclin E expression in (A) control, (B) SCC, (C) acute psoriasis, and (D) chronic psoriasis. Original magnification, x200.

layer (Fig. 1). Furthermore, the number of cells stained with cyclin D1 differed psoriasis group $\left(111.2 \pm 65.2\right.$ cells $/ \mathrm{mm}^{2}$; acute, $53 \pm 30.1$ cells $/ \mathrm{mm}^{2}$ and chronic, $157.8 \pm 41.6$ cells $\left./ \mathrm{mm}^{2}\right)$ compared with that of the normal skin $\left(81.5 \pm 10.6\right.$ cells $\left./ \mathrm{mm}^{2}\right)$ and SCC groups $\left(399 \pm 14.1\right.$ cells $\left./ \mathrm{mm}^{2}\right)\left(\chi^{2}=10.35, \mathrm{P}=0.016\right.$, Kruskal-Wallis test). A post hoc Mann-Whitney U test showed the chronic psoriasis group to have stronger cyclin D1 expression than that in than the acute psoriasis group (Table I).
Cyclin E expression was observed throughout the normal epidermis, showing positively stained nuclei and cytoplasm. In psoriasis, positively stained nuclei and cytoplasm were observed in the epidermis, especially above the suprabasal layer till the granular layer; this was not observed in normal epidermis or SCC (Fig. 2).

Total basal layer cell counts for $\mathrm{pRb}$ expression were found to be higher in the psoriasis group $\left(316.8 \pm 212.2 \mathrm{cells} / \mathrm{mm}^{2}\right.$; acute, 

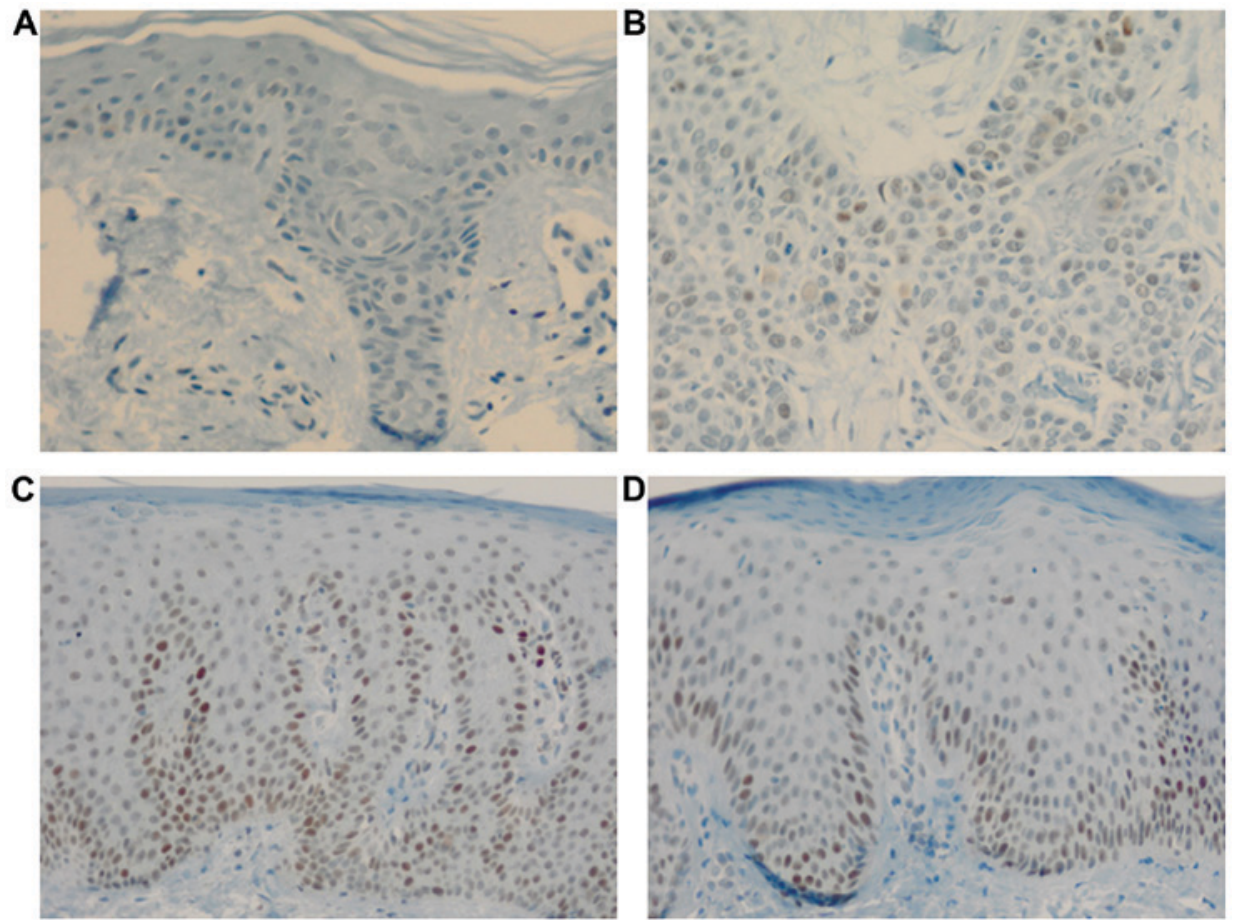

Figure 3. pRb expression. pRb expression in (A) control, (B) SCC, (C) acute psoriasis, and (D) chronic psoriasis. Total basal layer cell counts for pRb expression were found to be higher in the psoriasis group than in the control and SCC groups.
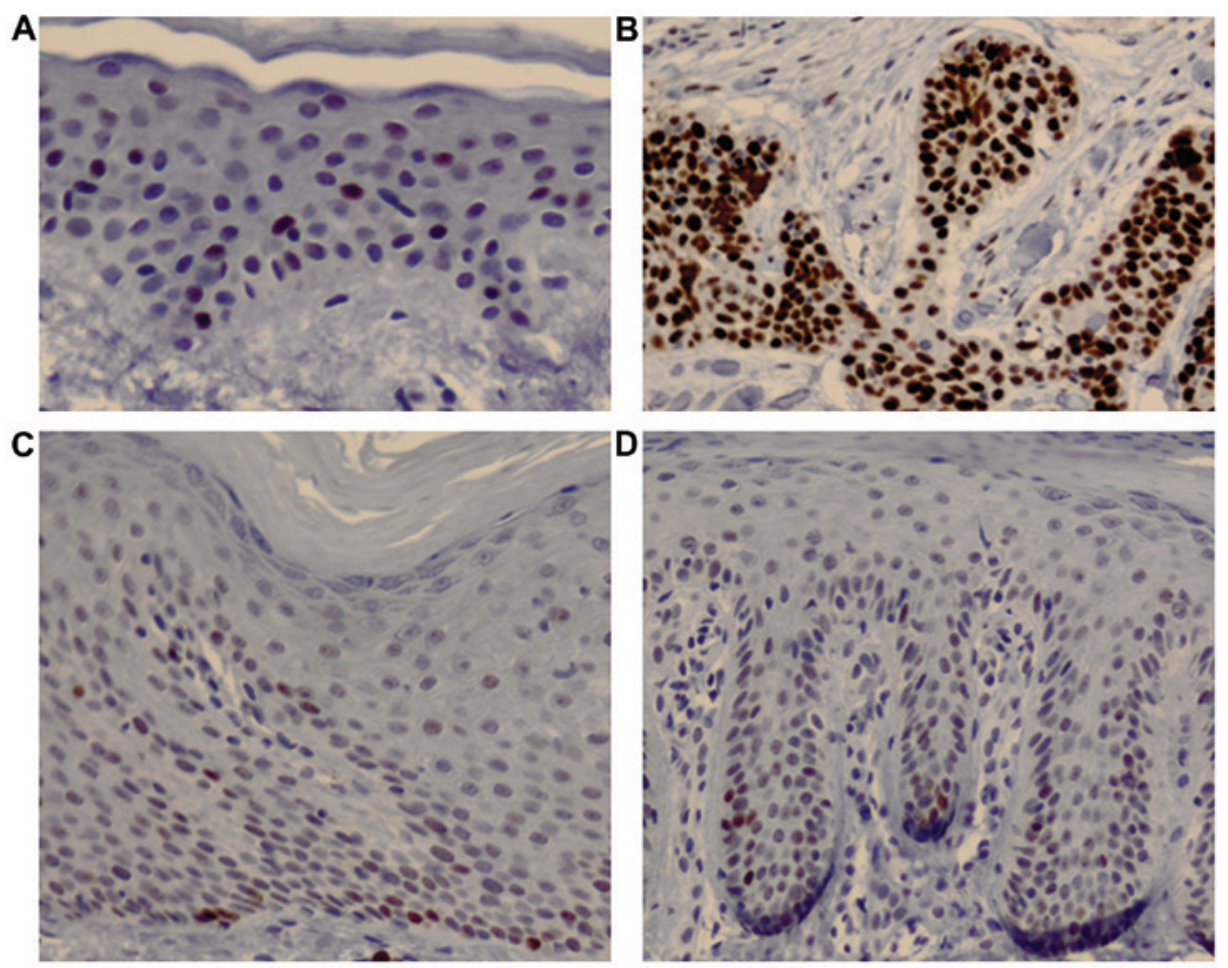

Figure 4. $\mathrm{p} 53^{\mathrm{WT}}$ expression. $\mathrm{p} 53^{\mathrm{WT}}$ expression in (A) control, (B) SCC, (C) acute psoriasis, and (D) chronic psoriasis groups. Strong p53 ${ }^{\mathrm{WT} / \mathrm{MUT}}$ expression was observed in SCC.

$141.6+113.4$ cells $/ \mathrm{mm}^{2}$ and chronic, $462.8+153.2$ cells $\left./ \mathrm{mm}^{2}\right)$ compared with the normal $\left(2.5 \pm 0.7\right.$ cells $\left./ \mathrm{mm}^{2}\right)$ and SCC groups $\left(58.5 \pm 14.8\right.$ cells $\left./ \mathrm{mm}^{2}\right)\left(\chi^{2}=10.91, \mathrm{P}=0.012\right.$, Kruskal-Wallis test) (Fig. 3). However, in the post hoc test, significant differences were found only between the acute and chronic psoriasis groups $(\mathrm{P}=0.16)$ (Table I).
In addition, total basal layer cell counts for p53WT expression were found to be higher in the psoriasis group $\left(25.1+15.8\right.$ cells $/ \mathrm{mm}^{2}$; acute, $13.61+4.9$ cells $/ \mathrm{mm}^{2}$ and chronic, $36.6+14.5$ cells $/ \mathrm{mm}^{2}$ ) compared with the normal epidermis $\left(5 \pm 1.4\right.$ cells $\left./ \mathrm{mm}^{2}\right)$. Strong p53 WT/MUT expression was observed in SCC (1063.5 \pm 328.8 cells $\left./ \mathrm{mm}^{2}\right)$ (Fig. 4). 

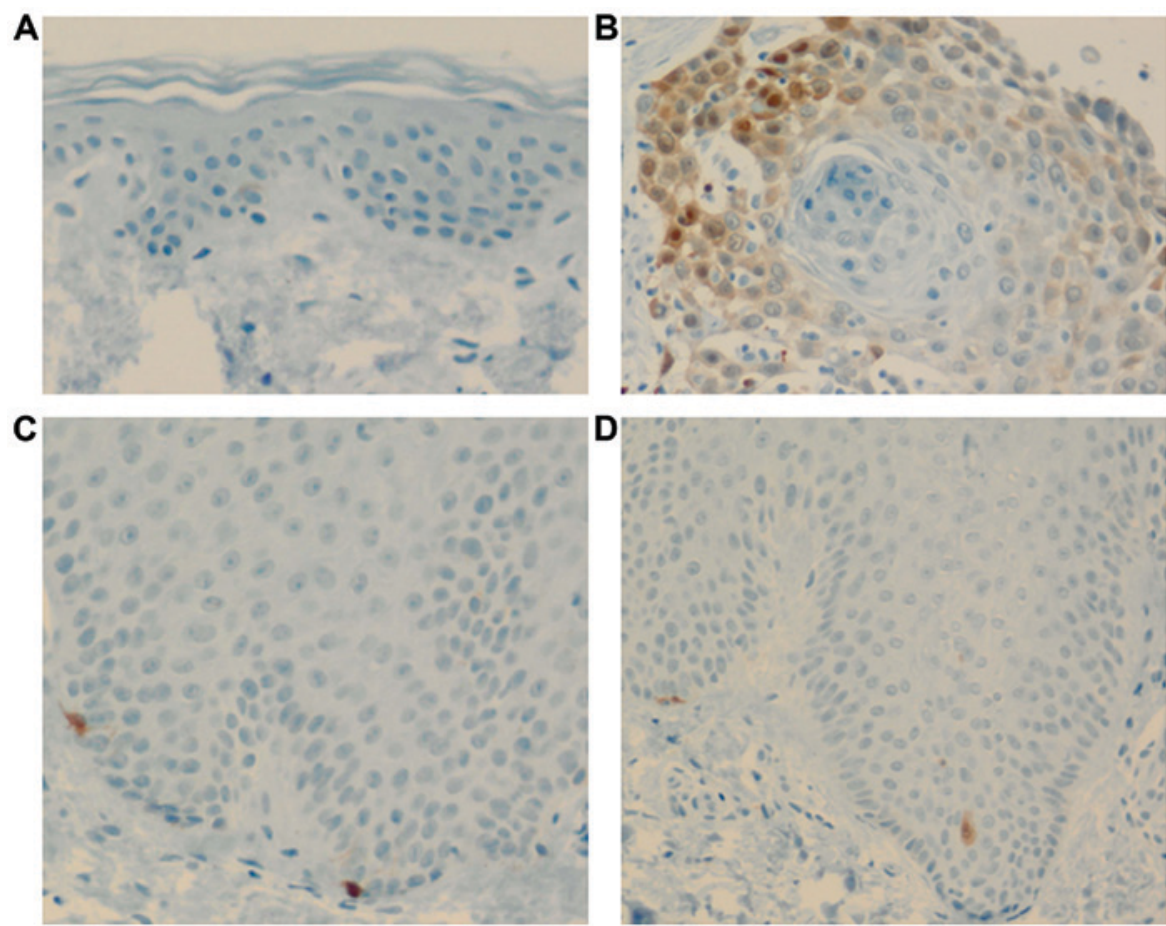

Figure 5. p16 expression. p16 expression in (A) control, (B) SCC, (C) acute psoriasis, and (D) chronic psoriasis groups. Expression of p16 tumor suppressor protein in the epidermis was very weak in the normal and psoriasis groups compared with that in the SCC group.
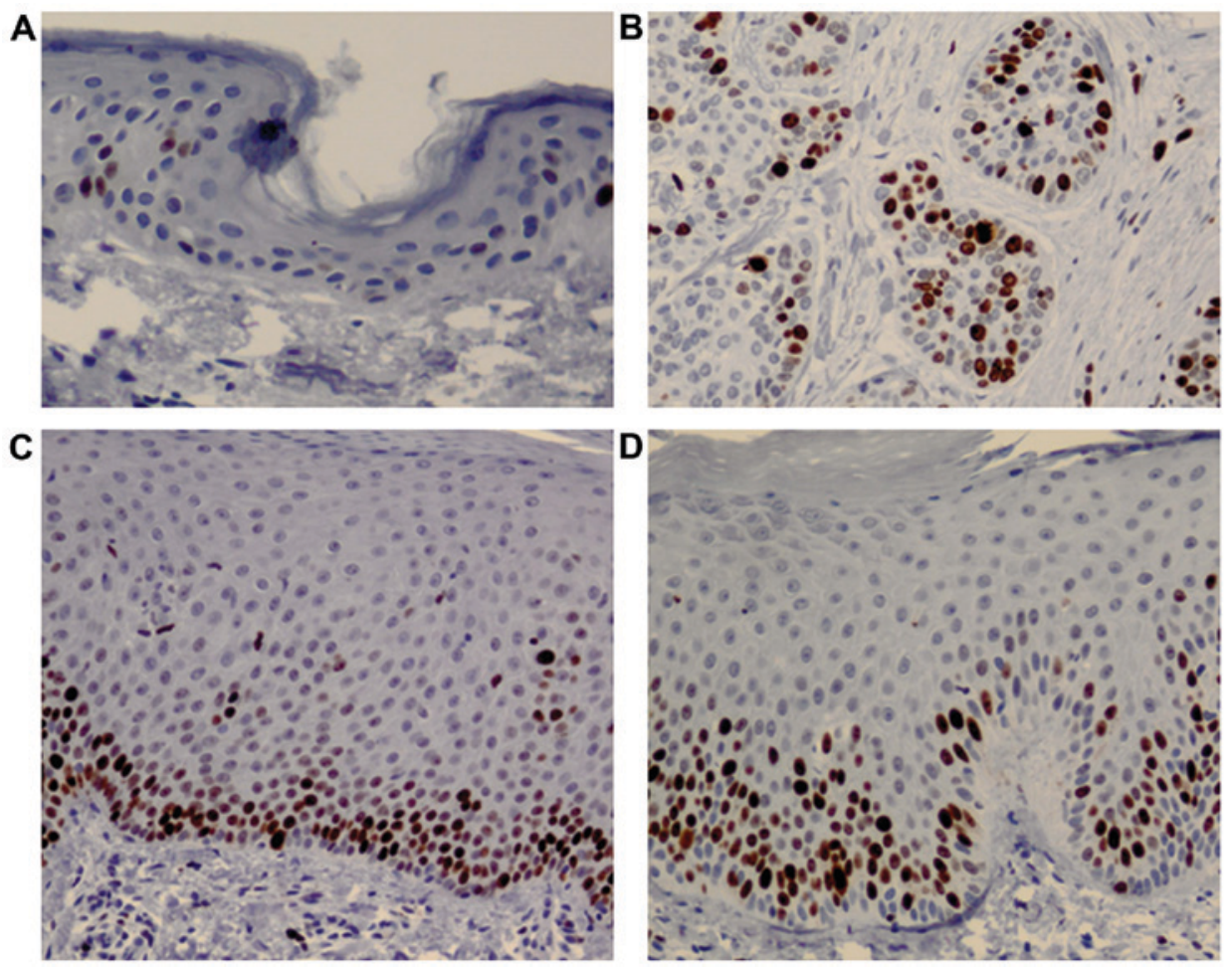

Figure 6. Ki-67 expression. Ki-67 expression in (A) control, (B) SCC, (C) acute psoriasis, and (D) chronic psoriasis groups. The number of Ki-67 immunoreactive cells was found to be higher in the psoriasis and SCC groups compared to that in the normal control group.

The expression of p16 tumor suppressor protein in the epidermis was very weak in the normal and psoriasis groups compared with that in the SCC group (Fig. 5).

Ki-67 immunoreactive cells were found to be higher in the psoriasis group $\left(452.9 \pm 242.5\right.$ cells $/ \mathrm{mm}^{2}$; acute, $267.2+109.6$ cells $/ \mathrm{mm}^{2}$ and chronic, $607.6+211.6$ cells $/ \mathrm{mm}^{2}$ ) compared withthenormalepidermis group $\left(38.5 \pm 4.9 \mathrm{cell} / \mathrm{s} / \mathrm{mm}^{2}\right)$. $\mathrm{Ki}-67$ expression levels in psoriasis were similar to those in SCC (498 \pm 134.3 cells/mm²) (Fig. 6).

However, the Kruskal-Wallis one-way ANOVA and Mann-Whitney U test for the cell count $/ \mathrm{mm}^{2}$ in all immunostaining results in the epidermal layer among psoriasis, control, 
A

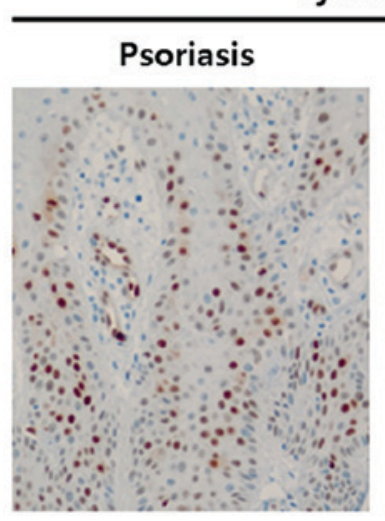

Cyclin D1

\section{Treated-psoriasis}
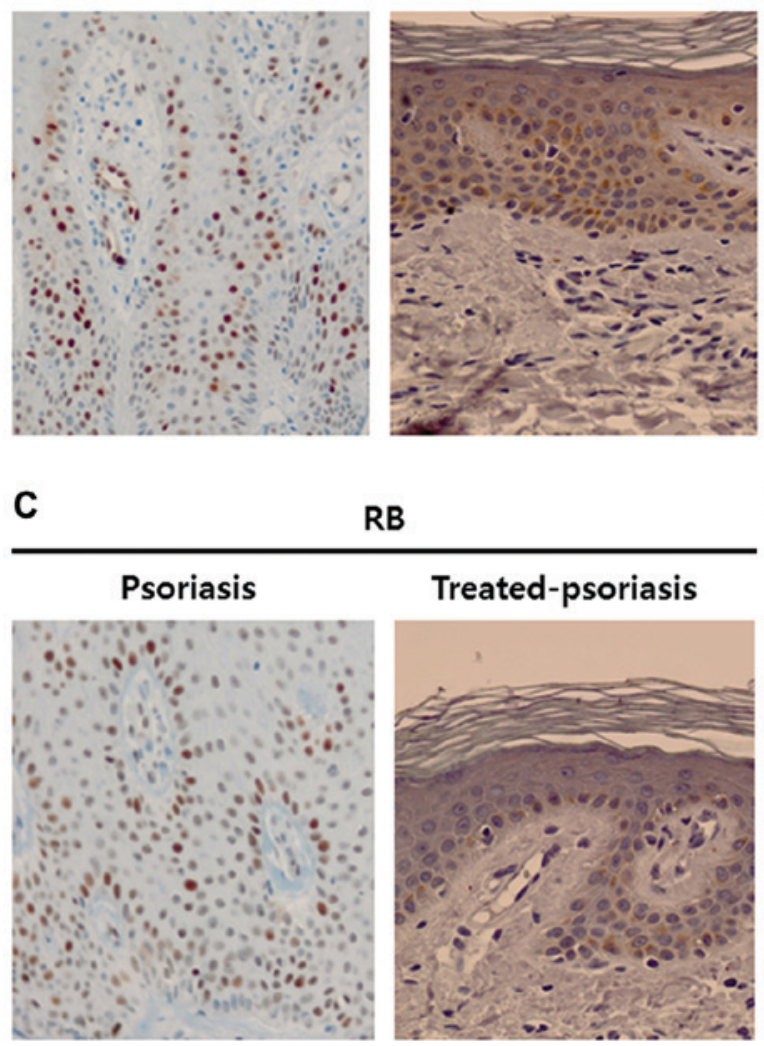

RB

\section{Treated-psoriasis}

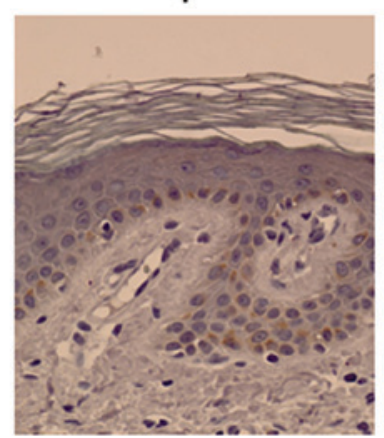

B

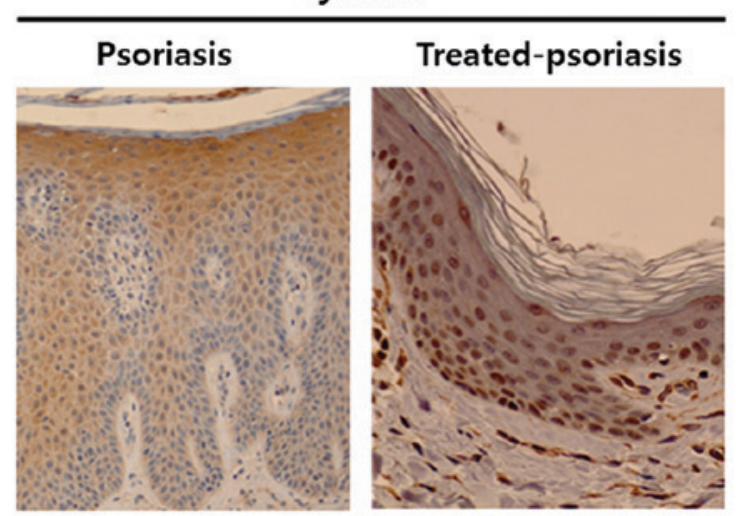

D

$\mathrm{Ki}-67$

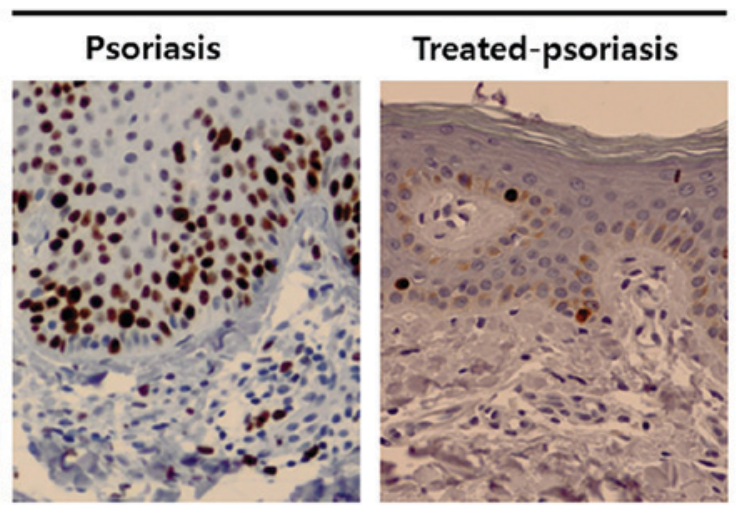

Figure 7. Comparison of expression by immunohistochemical analysis before and after treatment for psoriasis. The patient has been treated by methotrexate (10 mg/week) combined with topical calcipotriol/betamethasone ointment for 5 months. Skin samples were biopsied in the same psoriasis skin lesions before and after treatment. Comparative expression of (A) cyclin D1, (B) cyclin E, (C) pRb, and (D) Ki-67 in psoriasis skin lesions before and after treatment.

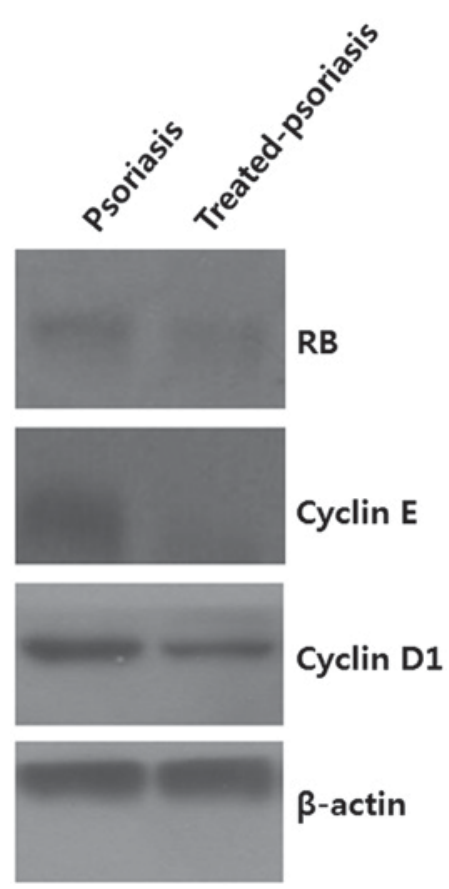

Figure 8. Comparison of expression by western blot analysis before and after treatment for psoriasis. The patient has been treated by methotrexate (10 mg/week) combined with topical calcipotriol/betamethasone ointment for 5 months. Skin samples were biopsied in the same psoriasis skin lesions before and after treatment. A comparative western blot analysis of cyclin D1, cyclin E, pRb, and Ki-67 expression before and after treatment. and SCC groups showed no statistically significant differences. The only significant difference was between the acute and chronic psoriasis groups (Table I).

Expression of cyclin D1, cyclin E, pRb, and Ki-67 in treated psoriatic skin lesions. We investigated whether the expression patterns of cell cycle regulatory proteins in psoriasis were normalized in treated psoriatic skin lesions. Immunohistochemical analysis revealed that the expression of cyclin D1, cyclin E, pRb, and Ki-67 decreased in treated psoriatic skin, and was similar with that of normal epidermis (Fig. 7). Consistent with immunohistochemical data, western blot analysis also showed that the expression levels of cyclin D1, cyclin E, pRb, and Ki-67 were markedly decreased in treated psoriatic lesions (Fig. 8).

\section{Discussion}

Psoriasis is a complex epidermal disorder characterized by keratinocyte hyperproliferation and abnormal differentiation owing to intricate interactions with the immune system $(15,16)$. Even though hyperproliferation and abnormal differentiation are the hallmarks of psoriasis, epidermal carcinogenesis is not observed in psoriatic skin lesions. To elucidate why psoriasis does not transform into malignancy under hyperproliferation of keratinocytes, we compared the expression levels of $\mathrm{p} 53$, 
$\mathrm{pRb}$, and cell cycle regulatory proteins in psoriatic skin lesions to those of SCC tissues.

The upregulation of cyclin D1 is well-established in hyperproliferative tissues $(10,11)$. In this study, we found that cyclin D1 was overexpressed in thick plaques of chronic psoriasis and SCC tissues. When compared to the normal epidermis and acute psoriatic epidermis, cyclin D1 in chronic psoriatic epidermis had a different pattern in terms of localization and expression level. We found that cyclin D1 immunoreactivity in chronic psoriasis was demonstrated as strong positive staining among several normal stained nuclei and at regular intervals in the basal layer. This finding is in agreement with previous studies, which also found increased cyclin D1 expression in psoriasis $(8,17,18)$. However, further studies are warranted to elucidate whether the cells in basal layers that were strongly positively stained for cyclin D1 are psoriatic stem cells or transient amplifying cells, which are important in the hyperproliferation of the epidermis.

Furthermore, p16 tumor suppressor protein showed weak activity in the psoriasis group compared to that in the SCC group. The increased expression level of p16 inhibits cell cycle progression and induces cell senescence and the prevention of aberrant cell proliferation $(19,20)$. Our data suggested that p16 may not be involved in the process of hyperproliferation to inhibit cell cycle progression, such as processes underlying SCC. These findings are in agreement with those of previous studies, indicating a low basal level of p16 in psoriasis (17). The levels of cyclin D1, cyclin E, and Ki-67 decreased significantly after psoriasis treatment in this study, which is also in accordance with previous studies (18). From these findings, we conclude that altered expression of cyclin D1 and cyclin E may contribute to the proliferation of psoriatic lesions. The phosphorylation status of $\mathrm{pRb}$ is specifically regulated by the activities of cyclin D1, cyclin E, and p16 $(21,22)$. In this study, chronic psoriatic skin lesions showed increased expression of cyclin D1 and cyclin E and low expression of p16 compared to those of the normal epidermis. According to these data, $\mathrm{pRb}$ phosphorylation in psoriasis may be increased by the activity of cyclin D1 and cyclin E. In this study, psoriatic epidermis showed a higher expression of $\mathrm{pRb}$ than that of normal epidermis.

In terms of expression patterns of cyclin D1, cyclin E, and p16, psoriatic skin lesions may easily transform into malignancies under long inflammatory processes, such as actinic keratosis (23). Our data suggested that increased expression of p53 in chronic psoriatic skin lesions could inhibit malignant transformation and create homeostasis between normal and hyperproliferative epidermal conditions. The involvement of the hyperproliferative state in psoriatic skin lesions is observed in the basal layer of the epidermis, which is supported by a high labeling index with Ki-67. Our data showed a similar distribution of p53- and Ki67-positive cells, which supports the hypothesis that increased proliferation enhances wild-type p53 protein synthesis for the prevention of malignant transformation (24). Indeed, p53 mutation gives a chance for the epidermis to undergo malignant transformation under constant inflammatory stress, e.g., in actinic keratosis and SCC (25). Fortunately, p53 mutation is not observed in psoriatic skin lesions. Normal p53 plays an important role in preventing psoriatic carcinogenesis.
It has been still largely unknown which mechanisms contribute to transit acute form psoriatic papules into chronic plaques form psoriasis. Our data indicate that up-regulation of cyclin D1 and cyclin E plays important roles to drive maturation and hyperproliferation of epidermis, eventually forming of thick plaques in psoriasis.

In conclusion, we demonstrated that altered expression of cyclin D1 and cyclin E may be involved in cell cycle progression in psoriatic epidermis, whereas p53 may be playing an important role for the prevention of malignant transformation under a hyperproliferative state in psoriasis.

\section{Acknowledgements}

The present study was supported by the Bisa Research Grant of Keimyung University in 2012.

\section{References}

1. Deng Y, Chang C and Lu Q: The inflammatory response in psoriasis: A comprehensive review. Clin Rev Allergy Immunol 50: 377-389, 2016.

2. Nestle FO, Kaplan DH and Barker J: Psoriasis. N Engl J Med 361: 496-509, 2009.

3. Weinstein GD, McCullough JL and Ross P: Cell proliferation in normal epidermis. J Invest Dermatol 82: 623-628, 1984.

4. Huang T, Lin X, Meng X and Lin M: Phosphoinositide-3 kinase/protein kinase- $\mathrm{B} / \mathrm{mammalian}$ target of rapamycin pathway in psoriasis pathogenesis. A potential therapeutic target? Acta Derm Venereol 94: 371-379, 2014.

5. Faes S and Dormond O: PI3K and AKT: Unfaithful partners in cancer. Int J Mol Sci 16: 21138-21152, 2015.

6. Sticozzi C, Belmonte G, Cervellati F, Di Capua A, Maioli E, Cappelli A, Giordani A, Biava M, Anzini M and Valacchi G: Antiproliferative effect of two novel COX-2 inhibitors on human keratinocytes. Eur J Pharm Sci 49: 133-141, 2013.

7. Bhatt KV, Spofford LS, Aram G, McMullen M, Pumiglia K and Aplin AE: Adhesion control of cyclin D1 and p27Kip1 levels is deregulated in melanoma cells through BRAF-MEK-ERK signaling. Oncogene 24: 3459-3471, 2005.

8. Sezer E, Böer-Auer A, Cetin E, Tokat F, Durmaz E, Sahin S and Ince U: Diagnostic utility of Ki-67 and Cyclin D1 immunostaining in differentiation of psoriasis vs. other psoriasiform dermatitis. Dermatol Pract Concept 5: 7-13, 2015.

9. Zhu W, Li J, Su J, Li J, Li J, Deng B, Shi Q, Zhou Y and Chen X: FOS-like antigen1 is highly expressed in human psoriasis tissues and promotes the growth of HaCaT cells in vitro. Mol Med Rep 10: 2489-2494, 2014.

10. Lavoie JN, Rivard N, L'Allemain G and Pouysségur J: A temporal and biochemical link between growth factor-activated MAP kinases, cyclin D1 induction and cell cycle entry. Prog Cell Cycle Res 2: 49-58, 1996.

11. Palmero I and Peters G: Perturbation of cell cycle regulators in human cancer. Cancer Surv 27: 351-367, 1996.

12. Sheaff RJ, Groudine M, Gordon M, Roberts JM and Clurman BE: Cyclin E-CDK2 is a regulator of p27Kip1. Genes Dev 11: 1464-1478, 1997.

13. Flatt PM, Tang LJ, Scatena CD, Szak ST and Pietenpol JA: p53 regulation of $\mathrm{G}(2)$ checkpoint is retinoblastoma protein dependent. Mol Cell Biol 12: 4210-4213, 2000.

14. Gire V and Dulic V: Senescence from G2 arrest, revisited. Cell Cycle 14: 297-304, 2015.

15. Rashmi R, Rak KS and Basavaraj KH: A comprehensive review of biomarkers in psoriasis. Clin Exp Dermatol 34: 658-663, 2009.

16. Schaller G and Meyer-Hermann M: A modeling approach towards epidermal homoeostasis control. J Theor Biol 247: 554-573, 2007.

17. Abou EL-Ela M, Nagui N, Mahgoub D, El-Eishi N, Fawzy M, El-Tawdy A, Abdel Hay R and Rashed L: Expression of cyclin D1 and p16 in psoriasis before and after phototherapy. Clin Exp Dermatol 35: 781-785, 2010. 
18. Miracco C, Pellegrino M, Flori ML, Vatti R, Materno M and Andreassi L: Cyclin D1, B and A expression and cell turnover in psoriatic skin lesions before and after cyclosporin treatment. Br J Dermatol 143: 950-956, 2000.

19. LaPak KM and Burd CE: The molecular balancing act of p16(INK4a) in cancer and aging. Mol Cancer Res 12: 167-183, 2014.

20. Kim WY and Sharpless NE: The regulation of INK4/ARF in cancer and aging. Cell 127: 265-275, 2006.

21. Lukas J, Parry D, Aagaard L, Mann DJ, Bartkova J, Strauss M, Peters G and Bartek J: Retinoblastoma-protein-dependent cell-cycle inhibition by the tumour suppressor p16. Nature 375: 503-506, 1995

22. Sherr CJ: The Pezcoller lecture: Cancer cell cycles revisited. Cancer Res 60: 3689-3695, 2000.
23. Brasanac D, Stojkovic-Filipovic J, Bosic M, Tomanovic N and Manojlovic-Gacic E: Expression of G1/S-cyclins and cyclin-dependent kinase inhibitors in actinic keratosis and squamous cell carcinoma. J Cutan Pathol 43: 200-210, 2016.

24. Yazici AC, Karabulut AA, Ozen O, Ekşioğlu M and Ustün H: Expression of p53 in lesions and unaffected skin of patients with plaque-type and guttate psoriasis: A quantitative comparative study. J Dermatol 34: 367-374, 2007.

25. Florence ME, Massuda JY, Soares TC, Stelini RF, Poppe LM, Bröcker EB, Metze K, Cintra ML and de Souza EM: p53 immunoexpression in stepwise progression of cutaneous squamous cell carcinoma and correlation with angiogenesis and cellular proliferation. Pathol Res Pract 211: 782-788, 2015.

(c) (1) (3) This work is licensed under a Creative Commons Attribution-NonCommercial-NoDerivatives 4.0 International (CC BY-NC-ND 4.0) License. 